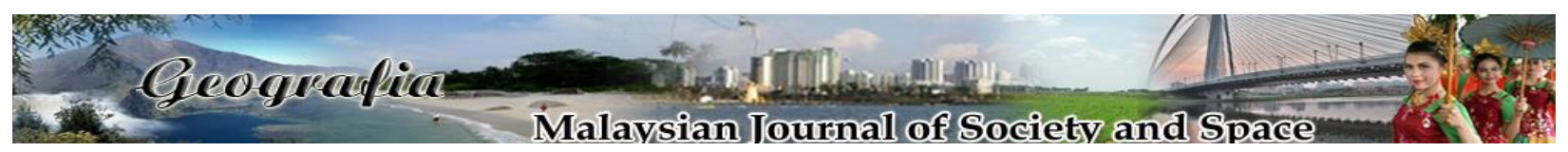

\title{
An interim evaluation of Penang's first bike-share scheme
}

\author{
Nadhrah A Kadir, Lim Ghee-Thean, Law Chee Hong \\ School of Social Sciences, Universiti Sains Malaysia \\ Correspondence: Nadhrah A Kadir (email: nadhrah@usm.my)
}

Received: 23 April 2019; Accepted: 25 July 2019; Published: 22 August 2019

\begin{abstract}
Bike-sharing schemes are gaining worldwide momentum as a non-motorized transport. The reasons why cities have jumped on the bandwagon of implementing a bike-share system are to reduce traffic congestion, to improve air quality and as an alternative transport option to move around cities. As part of the effort to be "cleaner, greener, healthier and safer," Penang Island has decided to launch the first bike-share scheme in Penang, making it the first state in Malaysia to ever implement a bike-sharing program with a docking station. While the existing literature on bike-sharing focuses on European and North American cities, less attention is given to experiences in South East Asia, especially small cities in the South East Asia. This paper aims to fill that gap by evaluating the performance of the pioneer of the bike-sharing program in Penang; i.e. the LinkBike. Using the inaugural data from LinkBike's first annual report, as well as data from personal interviews and grey literature, this paper attempts to understand the performance, opportunities and challenges facing LinkBike in its first year of operation. Essentially, results show that LinkBike was performing quite well considering it was the bike-share pioneer in Penang. This paper also highlights several opportunities such as attractive brands and effective outreach strategy and challenges in terms of payment method, safety concerns and lack of cycling culture. Understanding these motivators and constraints will better shape the performances of LinkBike in terms of ridership and cultivating the cycling culture in Penang.
\end{abstract}

Keywords: bike-share, cycling, LinkBike, non-motorized transport, performance, program evaluation

\section{Introduction}

Bike-sharing schemes are gaining worldwide momentum as an alternative and complementary mode of transport. There are many reasons why cities have jumped on the bandwagon of implementing a bike-share system. The most common reasons are to reduce traffic congestion, to solve the first and last mile problem and to improve the environmental issues related to transportation activities. The scheme started in the 1960s in Europe and over the years the 
development of the scheme has improved in line with the technological advancement. In Malaysia, two types of bike-sharing schemes were launched. LinkBike was first implemented in Georgetown, a small and populated city in Penang Island. The second bike-sharing scheme was Obike was launched in Kuala Lumpur and Johor Bharu. While Obike has shut down its operation due to many issues, LinkBike has continue its operation since it was first launched in 2016.

This paper aims to provide a better understanding of LinkBike's performance after one year of operation in Penang. It also seeks to explore the opportunities and challenges related to the implementation of the pioneer of the bike-share scheme in Malaysia. Mateo-Babiano (2015) and Mateo-Babiano et al. (2017) note small cities in Asian countries' slower uptake of bike-sharing programs due to several factors that are different from big cities. In addition, given that most literature on bike-sharing focuses on North America, Asia, Europe and Australia, we aim to fill the void by concentrating on the South East Asia experiences. More specifically, our focus is on Penang Island, a small island off the northern part of the Peninsular Malaysia. This paper is also significant in that it is the first that will document a systematic review of LinkBike in the first year of its operation. We attempt to answer two questions. How did the bike-sharing program perform in its first year of implementation? What are the opportunities and challenges facing the pioneering bike-sharing program in Penang? LinkBike is the first and the only bike-sharing with docking system launched in Penang, as well as in Malaysia: hence, it is important to learn about its performance, opportunities and challenges to improve its performance in the future.

\section{Literature review}

\section{Bike-sharing}

The history of bike-share begins in Europe: more specifically, it was first introduced in the Netherlands circa 1965 and has substantially grown across the globe throughout the years (Shaheen et al., 2011; Parkes et al., 2013). According to Fishman (2016), there were more than 700 bike-sharing schemes throughout the world in 2015. Audikana et al. (2017) are positive that this trend will persist. The features of bike-share vary, but essentially the general principle is that users acquire the bikes on an 'as-needed' basis with short-term access, usually within short distances around the city areas (Shaheen et al., 2012). Everything from pick-up to drop-off is conducted by users. Over the years, the bike-share schemes have evolved from no systematic payment or security measures (i.e. the first generation of bike-sharing of White Bikes) to docking stations and dock-less stations (Shaheen et al., 2011; Fishman, 2016). The most common type utilizes docking kiosks located at different parts of the city. Riders must pick up and return bikes to the docking stations (Fuller et al., 2011). On the other hand, the dock-less bike share, also known as 'free-floating', occurs when people can pick up the bicycle and return it to anywhere within the city (Shaheen et al., 2010). In this sense, the system is flexible. In recent years, the manual operation of bike-sharing has been upgraded to automated systems where people can rent the bikes through smart phone apps. Bike-sharing systems' advanced technology has enabled many features that benefit the providers, as well as the users. Perhaps the latest feature is integrating the bike-sharing system with other public transport. In this way, bike-sharing programs can provide a solution to the last-mile problem where they are strategically located near transport hubs, such as bus and train stations (Guo et al., 2017). 


\section{Benefits of bike-sharing}

Cycling has many benefits. Research consistently demonstrates that cycling is good for mental and physical health, the environment and the economy (Pucher \& Buehler, 2012; Shaheen et al., 2013; Mohd Noor et al., 2018). In addition, Walker (2017) had persuasively argued that cycling can lead to a "healthier, safer, equal, happier and prosperous world". In an effort to extend such benefits to a larger audience, bike-sharing schemes were introduced in many cities. In fact, cities around the world implemented bike-sharing schemes as solutions to many urban problems, such as to reduce traffic congestion and pollution. According to Shaheen et al. (2012), bike-sharing schemes have the potential to reduce GHG emissions.

Erçetin (2014) considered bike-sharing as one of the innovative urban transport systems to solve the problem of automobile dependency. For instance, for a trip of under one mile, Americans tend to drive almost 70 per cent of the time (Buehler, 2014). Hence, one of the benefits of bike sharing is that it can encourage users to leave their private vehicles behind for short-distance trips. One urban transportation issue is the disconnect between transit modes and users' locations, which, in turn, has discouraged users to opt for mass transit (Pucher \& Buehler, 2012). A bike-sharing system can work well when it is integrated with public transport as a solution to this issue, which is also known as the first-and-last-mile problem. In fact, in recent years, many bike-sharing schemes have attempted to integrate their system with other modes of public transport. Furthermore, there are plentiful kiosks conveniently located near public transport hubs.

In general, as discussed above, bike-sharing schemes offer similar benefits to riding one's bicycle. Additionally, they provide an alternative mobility option for those who may not own a bicycle or in circumstances where they cannot ride their own bikes. For example, this may include tourists or visitors and those who just want to enjoy 'hassle- and maintenance-free bicycle access' (Shaheen et al., 2012, 184).

\section{LinkBike in Penang}

Like most typical cities in South East Asia, Penang experiences terrible traffic congestion on a regular basis. The situation is of great concern to the state government and citizens and the government has taken some steps to overcome the problem. One of the efforts is to encourage cycling among the public. For the past couple of years, it has become very popular in Penang but is not a unique situation. Historically, the bicycle used to be a means of transport in Penang but, over the years, the majority of Penangites no longer considered the bicycle as a mobility option. Many factors have contributed to the shift to rapid motorization: rapid development in Penang, such as the expansion of industrialization, constructions of roads and highways, and the national car policy, among others (Ladin et al., 2014).

Most cyclists in Penang are still considered to be recreational cyclists. Commuting by bicycle is still at an early stage. When the current government took over Penang in 2008, it pledged to make Penang greener, cleaner, safer and healthier. It was an effort by the state government to transform Penang into a sustainable and habitable city (Lim, 2016). Cycling is commonly known for being friendly to personal and public health, the environment and the economy. Not surprisingly, there are many cycling events and campaigns organized by cycling clubs in Penang. The state government is seen as supportive in promoting cycling in Penang, especially on the island. This is evidenced by the existing cycling infrastructure, such as 
dedicated cycling lanes, sharrows, bicycle sign boards around the island and bicycle parking (Ong, 2017). The first phase of a cycling lane connecting the Queensbay Mall to George Town, which is the capital city of Penang Island has been completed. The second phase is set to be finished in a few years.

LinkBike is a public-private partnership operated by the Penang Island City Council and a private company - Fast-Rent Bike. Similar to Hangzhou Public Bicycle in China, the local government launched the effort for the bike-sharing scheme, initiated with similar objectives of tackling traffic congestion (Shaheen et al., 2011). According to Taha (2018), there are three determinant factors of the docking stations' locations in Penang. First is visibility. This is crucial, as bike-sharing is new in Georgetown and LinkBike is pioneering Penang's bike-sharing program. The second factor is the UNESCO Heritage site status, which is predominantly a tourist area. Several stations are in the heritage areas. In fact, many tourists ride the bikes to explore such areas. The last factor is the centre of commercial and recreation facilities, hotels, hospitals, public transport and education institutions. These are common indicators of other successful bike sharing systems, as students, visitors and workers tend to flock around this area. LinkBike had strategized its locations in areas where people can take the bikes to run errands within a short distance, riding along the coast for recreation, visiting places of interests within the heritage sites and as a solution for last-mile problems.

Within a year of operation, LinkBike operates at a scale of 250 bicycles: 135 are deployed for the users and 115 are kept as reserves for events and break-down replacements. The shared bicycles are deployed in 25 kiosks or stations offering 300 dockings. 19 of these stations are installed in the Georgetown area. Three more stations can be found at the south-east of Penang (Karpal Singh Drive, Summerton and Queensbay). The rest are available at the north of Penang Island (Gurney area). The locking system is automatic, making it easier for users to pick-up and drop-off at any of the kiosk stations. LinkBike has maintained the ratio of bicycles to the dockings at 1:2 at each station. All kiosks and dockings are functioning and in fact, the bicycles offered were spared from theft and vandalism with zero reports for either. These figures indicate some level of acceptance among the public regarding the concept of bike sharing

Prior to 2018, 95\% of LinkBike users were using the mobile app to complete the registration. Only a few of them (5\%) registered themselves manually by purchasing the membership card at the Light's Café or promotion booth. After the registration via app, users can scan the OR code at the dock station. In the beginning, LinkBike users could use only Braintree payment gateway for credit card payment through a mobile phone app, but in 2018, a credit card with any payment gateway, such as Visa or Mastercard, was used for the service. In 2018, LinkBike was also expecting the same proportion (95\%) of LinkBike users employing the mobile app for registration. The company, consequently, has prepared for upgrading of the app to become more user-friendly and informative. Taha (2018) notes the inconvenience of registration using a credit card. This is because some groups with lower income, such as students, might not own credit cards. Alternatively, users can visit the LinkBike office in George Town to purchase the membership card. The required deposit for a card is RM 100, which is refundable. LinkBike notes that the card is not attractive because of a higher deposit.

Users can order a daily, weekly, monthly or yearly pass. The rate is RM2 for a 1-day pass, RM 3 for a 2-day pass, RM 4 for a 3-day pass and RM 20 for a 30-day pass and RM 30 for 1year pass. The charge works in that the first 30 minutes of a ride is free, and the subsequent charge is RM 1 per hour. The fee system structure encourages short distance rides with minimum 
charges. According to Taha (2018), LinkBike depends on a registration deposit and membership fees to maintain the cost for the bikes and their maintenance.

\section{Methods and study area}

This study applied quantitative and qualitative approaches. The quantitative approach draws on inaugural data from LinkBike's first year annual report in which descriptive analysis was conducted. Descriptive analysis described the basic features of data obtained from annual report using tables and graphs. Similar to Ahillen et al. (2016), the analysis explored membership and ridership trends and neighbourhood performance by describing patterns and gaining insights into the performance. The qualitative approach was based on personal interviews with the staff of LinkBike (i.e., the Chief Executive Officer, the Marketing Officer and Operating Officer) and grey literature in which we discuss the motivators and constraints for LinkBike in its first year of operation.

Penang is one of thirteen states in Malaysia and is located north of the Peninsular Malaysia. It is divided into two parts: the Island of Penang and the mainland. The capital city, George Town is located in the island. This research has focused on Penang Island because LinkBike is the first and the only bike-sharing with docking system launched in Penang, as well as in Malaysia.

\section{Results and discussion}

\section{Performance}

The first part of this section addresses the performance of LinkBike, based on membership and ridership, monthly ridership, neighbourhood performance and package ordered. Although LinkBike's operation is relatively short, it has produced some encouraging statistics. Within a year of the launch, at the end of 2016, it provided services to 33,806 of locals and foreigners. 30,197 people became members: a large portion of the riders joined via mobile application $(30,039)$ and the remaining used the membership cards. In fact, citizens from 61 countries from all main regions in the world have used this service. Malaysians are at the top of the ranking, where they comprise $71.64 \%$ of the users. This is followed by China (3.05\%), Indonesia (3.04\%), Singapore (2.25\%), Japan (2.01\%), Taiwan (1.8\%), Thailand (1.58\%), Australia $(1.3 \%)$, The Netherlands (1.18\%) and Vietnam (0.98\%).

Ridership was also encouraging. On average, there were 93 riders per day and the maximum usage per bicycle was 3 trips per bicycle per day (Karpal Singh Drive) (Table 1). However, the other stations received lower usage, most probably because the scheme just started. Karpal Singh Drive has high frequency of usage per bicycle, which is encouraging since it is only slightly less compared to similar bike-sharing programs in other developed countries. For instance, the average use per bike was 3-8 trips per bicycle per day globally (Fishman et al., 2013), supporting the argument that the shared bicycle programs were well-received by the community and visitors. 
Table 1. Daily usage by location

\begin{tabular}{lc}
\hline Location & $\begin{array}{c}\text { Daily usage } \\
\text { (Numbers per bike) }\end{array}$ \\
\hline Karpal Singh Drive & 2.8 \\
Lebuh Acheh & 2.1 \\
OCBC Bank, Summerton & 1.3 \\
City Hall, Armenian Street & 1.2 \\
Kapitan Keling & 1.1 \\
Campbell Street & 0.9 \\
Lebuh Light, Muntri, 1' ${ }^{\text {st }}$ Avenue & 0.8 \\
Gama & 0.6 \\
Bishop Street RHB, Evergreen Hotel, MWE SWOPT, Gurney Paragon & 0.5 \\
Pangkalan Weld, Beach Street, Kelawai Road, Queensbay & 0.4 \\
Source: LinkBike Report, 2017 &
\end{tabular}

Figure 1 illustrates LinkBike's monthly ridership from December 2016 to December 2017. Although there was instability in the number of users throughout that period, the usage was higher after May, which is the second half of the data duration. This is a sign that the response from the public became more positive. The positive response is crucial for the sustainability of the bike-sharing business model. The figures were higher in July and December and the main factor could be the holiday seasons in Malaysia and overseas. There was a moderately positive correlation $\left(\mathrm{R}^{2}=0.55\right)$ between the time period and monthly rides, meaning that LinkBike has increased its monthly ridership over time.

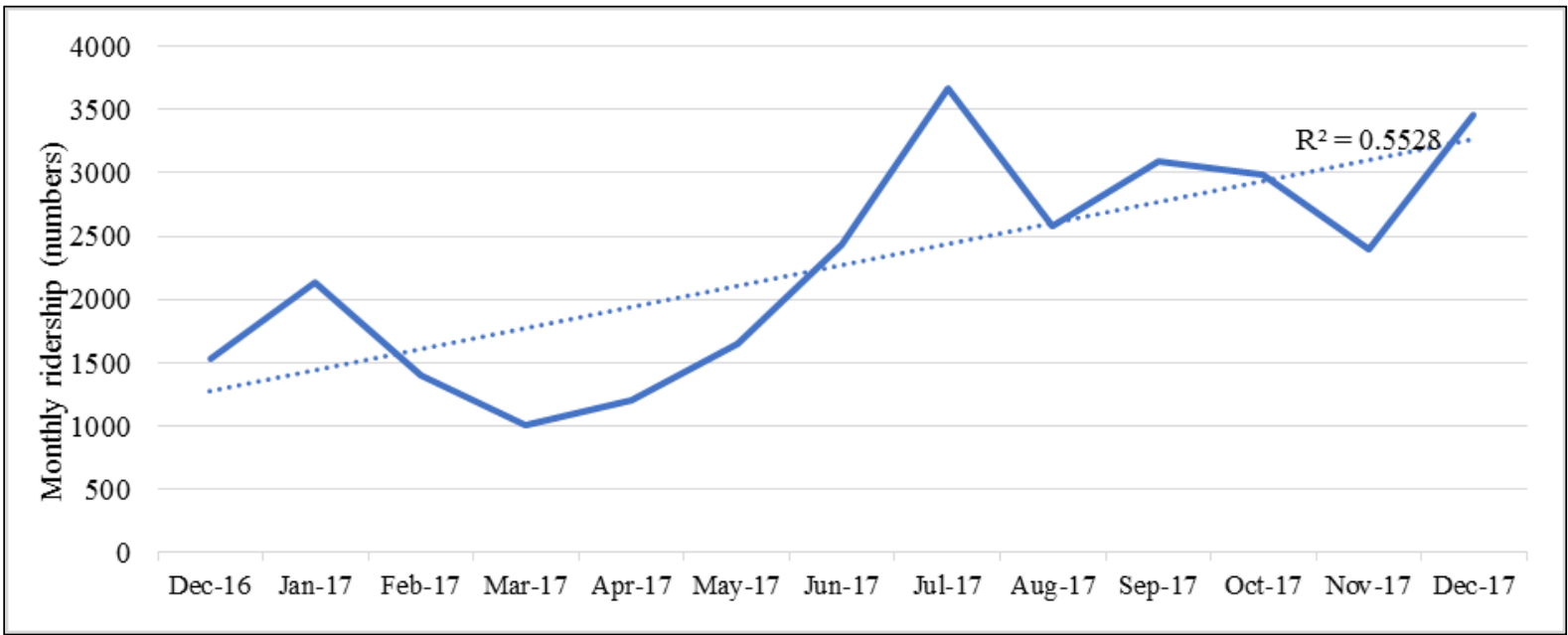

Source: LinkBike Report, 2017

Figure 1. LinkBike's monthly ridership

The most popular station was Karpal Singh Drive which is located at the residential and recreational area (4312 times). Lebuh Acheh station, which has the second-highest number (3440 times), is located at a popular tourism spot and is proving to be popular. This is followed closely by the OCBC Bank station (2196 times) and Summerton station (892 times). The OCBC Bank station is also in a tourist area and a main commercial area where many financial institutions set up their offices. The Summerton station, on the other hand, is in a newly-established residential area where there are several apartments. It is also close to one of the biggest shopping malls in 
Penang. There is a high potential to grow the rider base by installing more stations in the residential areas because it seems as though bike sharing is a viable option for travelling short distance. This finding is similar to Fishman et al. $(2013,13)$ where it was suggested that "the proximity of residential addresses to docking stations appears to have a powerful influence over propensity to use a bike-share program." In addition, stations located at Kapitan Keling (779 times) and Armenian Street (1363 times) were also performing well. This is because both locations, including Lebuh Acheh, are in the UNESCO Heritage Area, which tends to draw many tourists. Taha (2018) points out that tourists and visitors in the Heritage Area could potentially use LinkBike to explore the Penang Heritage Trail.

According to Figure 2, most LinkBike users access the service daily. This suggests that LinkBike provides one of the travel options for visitors or locals to move around the Georgetown area. The low use for the other packages suggests that most of the tourists could move to further areas, unreachable by the shared bicycles, after visiting Georgetown. Compared to other packages, the lower number of users who subscribed to the one-year package also proves that most of the users were tourists. There was a moderately positive correlation $\left(\mathrm{R}^{2}=0.56\right)$ between the time period and package ordered, meaning that LinkBike has increased its package ordered, over time.

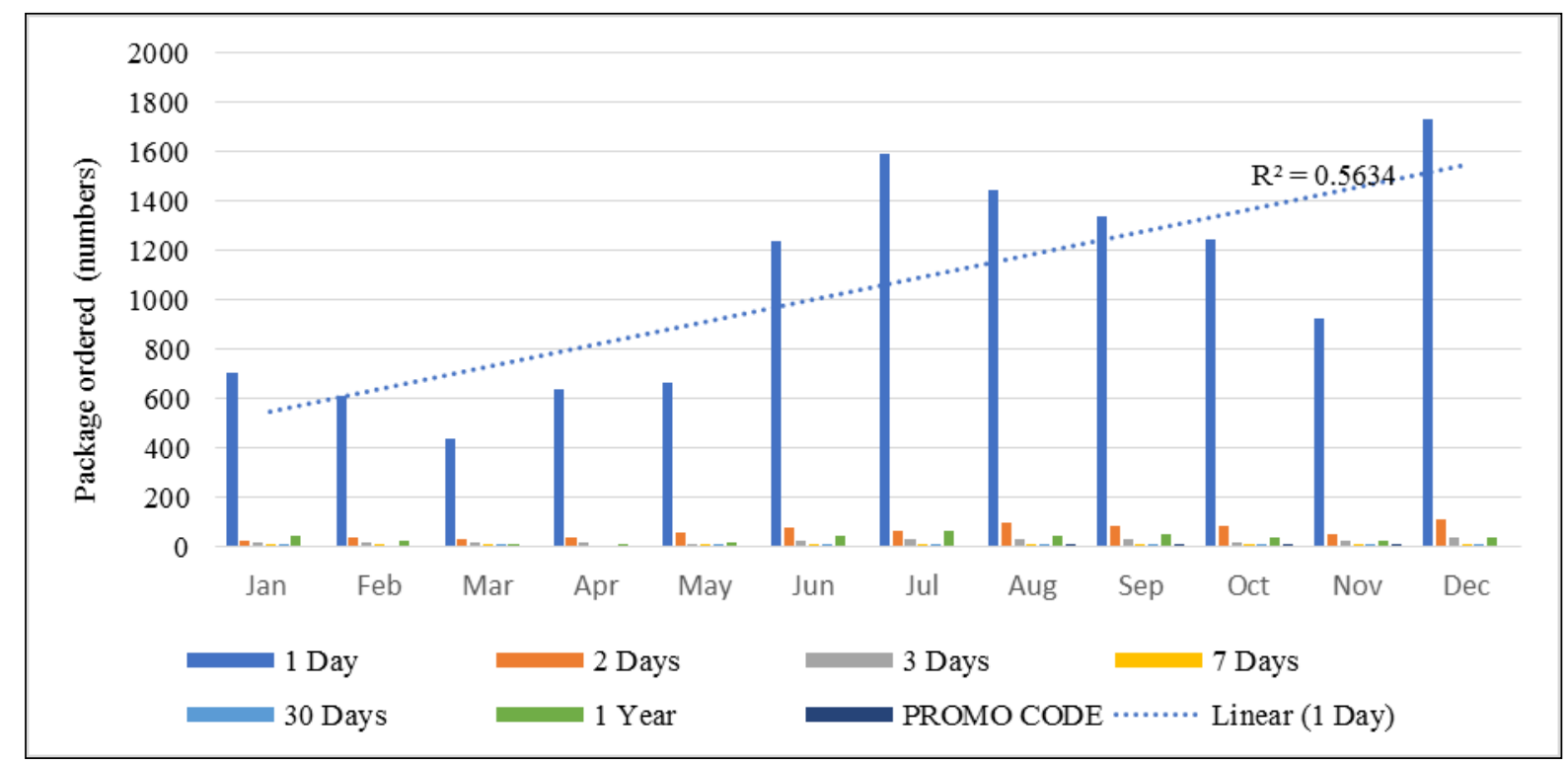

Source: LinkBike Report, 2017

Figure 2. Package ordered 2017

\section{Motivators and constraints}

The motivators are its brand and mission, marketing and outreach strategy, cycling infrastructure, cycling awareness and no bicycle theft and vandalism.

The name LinkBike carries a strong brand identity of bike-sharing with the tagline of 'Cycling Made Easy.' This is coupled with an attractive and colourful identifiable logo. The criteria are very much in line with The Bikeshare Planning Guide $(2018,59)$ suggestion, in which the bike-share brand presents "a professional, modern image and distinguishes it from other urban transport options." Taha (2018) notes that LinkBike has a clear vision and mission, 
as well as a good strategy from the outset. According to LinkBike, its mission is to reduce and, to some extent, replace the use of motor vehicles for short-distance commuting. This goal, in turn, will reduce traffic congestion and reduce environmental pollution. This mission is in line with that of bike-sharing programs world-wide. For instance, Midgley (2009, 24) pinpoints that, typically, "bike-sharing systems are introduced to increase mobility choices, improve air quality and reduce congestion." After one year of operation, it is difficult to prove that LinkBike can achieve its goal to reduce car dependence. Taha (2018) points out that the three main reasons for users to try LinkBike are curiosity to try a new activity, for environmental reasons and for recreation.

In terms of strategy, LinkBike has carefully selected locations that are deemed strategic, such as in tourist spots, education, financial, health, recreation, residential and commercial areas. The company had been intensifying its marketing strategies to create public awareness of the bike-sharing scheme. It can be challenging, as LinkBike was the pioneer of the bike-sharing system in Penang. In addition, the state government, in collaboration with other stakeholders, such as cycling clubs, businesses, the education sector, health providers often organized cycling events in Penang. LinkBike frequently joined many of such cycling events. Many times, they coorganized the events and sponsored the shared bicycles.

As a pioneer of the bike-sharing scheme in Penang, it is crucial for LinkBike to educate and engage with the public to promote the programme. It is important to raise awareness of bikesharing goals. The company had been actively involved with activities that are able to promote the brand locally and internationally. In 2017, LinkBike had participated in 36 cycling and green events. Some of the events had been highlighted via social media, local newspapers and electronic media, such as 8TV, TLC and Discovery Networks. Conversely, the community outreach programmes were very inclusive and diverse in that they covered activities with school children, college students, public servants, cycling groups, businesses and private sectors, as well as NGOs. This is in line with the BikeShare Planning Guide's (2018) suggestion that the bikesharing program should commit to community engagement from the outset.

Undoubtedly, LinkBike was introduced at the right time, given that the state government has intensified the efforts of becoming the first cycling state in Malaysia (Buletin Mutiara, 2017). Among the initiatives were to build more cycling infrastructure, such as the 39-km dedicated cycling lanes, also known as the Coastal Cycling Route, which starts from Tanjong Tokong via George Town to Sultan Abdul Halim Muadzam Shah Bridge (the Penang Second Bridge). Part of the dedicated cycling lanes was the iconic spiral Harapan Bridge, which was completed for cyclists and pedestrians to cross the Bayan Lepas Expressway to the industrial areas on Sungai Nibong Expressway in Bayan Baru (Pavither, 2018). Indeed, one of the success factors for LinkBike is the existence of the cycling infrastructure especially the segregated bike lanes (Taha, 2008). Hence, to some extent, the popularity of LinkBike depends on 'build it, and they will come.' Contrarily, improving the cycling infrastructure will enhance road safety for cyclists and will encourage the acceptance of the bike-share program (The Bike Share Planning Guide, 2018). In addition, several studies found that the presence of a cycling infrastructure, such as bike lanes, can influence the usage of the bike-sharing scheme (Wiersma, 2010; Buck \& Buehler, 2011).

The idea to implement the bike share scheme was initiated by the current Penang Island Mayor, Dato' A.R Yew Tung Seang, who was the former Director of Building Control. As a matter of fact, the Mayor himself is an avid cyclist who constantly supports the campaign of bike-commuting to work; i.e., Bike on Friday (BoF). Similarly, the bike-share scheme (Boseh) in 
Bandung, Indonesia was heavily supported by its Mayor, Ridwan Kamil, who also co-founded a bike-share scheme at the Institut Teknologi Bandung (ITB) in 2012. In line with the Cycling Embassy of Denmark's (2018) recommendation, decision-makers at all levels need to prioritize a cycling agenda for a strong cycling culture to exist.

Part of LinkBike's acceptance is due to the existence of a cycling awareness in Penang. Despite this, the bike share program in Penang has yet to be seen as an alternative mode of transport. People usually use LinkBike for recreational or fun rides (Taha, 2018). This finding is not surprising given the fact that cycling, as a way of commuting, has yet to become a norm in Malaysia. Nevertheless, the presence of cyclists certainly has created an awareness among other motorists and road users. Most notably, perhaps, was the effort to encourage Penangites to bikecommute. With full support from the state government, G-Club Penang Cyclist launched Bike on Friday (BoF) in 2015. The group gathers every Friday morning at the Queensbay Mall and cycle together on the $12 \mathrm{KM}$ dedicated cycling lanes into town. In town, everyone disperses to their workplace. This group has also been advocating for better cycling infrastructure in Penang (Sekaran, 2018). In 2011, the state government launched 'Car Free Day' on the third Sunday every month, in Georgetown area, to encourage people to undertake activities, including cycling on the roads.

According to DeMaio (2009), theft and vandalism pose a common threat to the success of the bike-sharing scheme. Nevertheless, increasingly technology has been able to solve the theft problem thanks to GPS tracking installed in the bikes. In addition, customers' credit cards can act as a guarantor should anything occur. The type of bicycle employed in bike-sharing programs is commonly designed in a way that is vandal-proof, such as having a strong and heavy frame, puncture-proof and wider tires and the need for special tools to disassemble the bikes (DeMaio, 2009). Not surprisingly, LinkBike reported zero cases of theft and vandalism. This experience is similar to the Hangzhou Bikesharing program (Shaheen et al., 2011). Hence, LinkBike has yet to implement any measures to disincentivize negative user behaviours, with penalties linked to users' accounts.

Notably, there are also some constraints in terms of payment method, safety concerns, and the lack of cycling culture. The use of credit cards as a payment method is regarded as one of the drawbacks for LinkBike. The payment method is viewed as a disadvantage for low-income groups, students, and those who prefer not to have a credit card. The reason for LinkBike to opt for such a payment method is because of the security on their side. Indeed, as The BikeShare Planning Guide (2018) suggests, while the intention of encouraging proper user behavior puts liability holds on users' credit cards, it has inadvertently discouraged accessibility for people without credit cards.

Safety concerns are the main reasons discouraging many people from cycling. As noted by Fishman et al. (2012, 2013), such issues are also common in other places around the world, such as in Australia, the United Kingdom, and North America. Similarly, safety tends to be the main issue for people taking up the bike-share program. This is also why a bike-commuting culture in Penang is almost non-existent. Hence, it will take some time for LinkBike to achieve its main goal as an alternative mode to motorized vehicles. In her survey, Taha (2018) pointed out that respondents view riding bicycles on shared roads with other motorized vehicles as a challenge. This is not surprising given that Penang Island is notorious for traffic congestion, especially during peak hours. According to the Penang Road Transport Department, the new registration of vehicles on the island continues to rise every year. In fact, the number of vehicles steadily increasing against the total size of George Town, which is relatively small compared to other 
cities, is quite alarming (Bernama, 2017). Similarly, Fishman et al. $(2013,17)$ also note that one of the safety concerns is related to "perceived risk of collision with motor vehicles", in addition to motorists' behavior and lack of bicycle infrastructure. Nonetheless, the most recent data from the United States shows that there have been no deaths from bike-sharing compared to regular biking (Martin et al., 2016). This report concluded that bike-sharing seems to be safer due to the design of the bicycles which are often sturdy, slower, and larger than personal bicycles.

Another issue is related to the perception of wearing a helmet while riding. Some studies found that bike-sharing schemes that mandate helmet law reduced the attractiveness of the program (Fishman et al., 2013; 2012). Moreover, Taha (2018) argues that the absence of mandatory helmet regulation reduces riders' trust toward the bike-sharing program because the law that mandates helmets could be perceived as 'the bike share program is safe.' On the other hand, The BikeShare Planning Guide (2018) proposed that helmet laws should not be mandatory, but the use of helmets could be encouraged through education.

As mentioned previously, cycle-commuting in Penang has yet to become a norm despite some consistent efforts by local cycling advocates and the local council. The cycling culture that does exist in Penang is mostly for recreation and sports-related events. For a bike-commuting culture to exist and flourish, it will take some time, dependent on many factors, such as cycling infrastructure, the attitude of the public, motorists' behaviour and most importantly, political will. While the state government continues to upgrade much of the cycling infrastructure, such as bike lanes and bike parking, there is still room for improvement. Many studies reveal that a lack of cycling infrastructure can discourage people from taking up the bike-sharing program (MateoBabiano et al., 2017). In fact, Midgley lists several criteria to assess whether a city is ready for the implementation of a bike- share program. The criteria are as follows:

"...A strong commitment to sustainable urban mobility and the promotion of cycling; a minimum standard of bicycle infrastructure for safe and convenient cycling; sufficient resources to achieve a real impact; and sufficient space for racks/parking to guarantee access to bicycles" $(2009,29)$.

Another barrier is the attitude and behaviour of motorists for cyclists. There are many instances where motorists act aggressively and demonstrate less respect toward cyclists. For instance, cycling infrastructure, such bike lanes and bike parking, are often occupied by motorbikes. To some extent, social change would require a robust political will. Indeed, as suggested by the Cycling Embassy of Denmark, "a strong bicycle culture requires long-term political commitment and priority" (Cycling Embassy of Denmark, 2018). While a vibrant cycling culture may seem to support the acceptance of bike sharing, there is no evidence that this is the case in Penang Island.

\section{Conclusion}

The goal of this paper is to evaluate the performance and to understand the opportunities and challenges of the pioneer of bike sharing in Penang Island, LinkBike, after it was launched in late 2016. Based on our interim analysis, we argue that LinkBike has relatively performed quite well. Our interim evaluation identifies several factors that have contributed to the acceptance of the 
bike share program. It is encouraging to note the acceptance despite some challenges that LinkBike needs to overcome to be an alternative mode of transport in the future.

As LinkBike is gaining more popularity, there is much room for improvement, especially in terms of upgrading the option for payment methods that will allow the use of debit cards for holistic convenience to ensure equal access for all walks of life. In support of an effort to increase the attractiveness of the program, the company can consider integrating the membership with public transport, such as Rapid Penang which is a public bus in Penang. Perhaps this initiative can help solve the first-and-last-mile problem. Bike-sharing could encourage bicycle commuting in that it has benefits against private bicycle ownership.

Penang is on the right track in promoting cycling following the initiative of launching the bike-share program. Bike-sharing can increase the presence of cyclists on the road and this will generate political support for cycling infrastructure and investments in the long run. While LinkBike has started to collaborate with other stakeholders, it is imperative for them to continue advertising the brand more broadly. There seems to be a lack of physical presence of the brand in public spaces in the form of billboards, bus shelters and public transport. Moving forward, in order to achieve the main goal of bike-sharing as alternative transport to car-driving, future studies could explore the issue of equity and accessibility and whether LinkBike has taken any efforts to reduce accessibility barriers. It is also important to identify other determinants that could potentially contribute to better acceptance of the scheme, such as a vibrant cycling culture and unwavering political support toward bike-sharing and the cycling agenda.

\section{Acknowledgements}

The authors acknowledge Penang Island City Council and LinkBike for the information and data they provided for this paper.

\section{References}

Ahillen, M., Mateo-Babiano, D., \& Corcoran, J. (2016). Dynamics of bike sharing in Washington, DC and Brisbane, Australia: Implications for policy and planning. International Journal of Sustainable Transportation, 10(5), 441-454.

Audikana, A., Ravalet, E., Baranger, V., \& Kaufmann, V. (2017). Implementing bikesharing systems in small cities: Evidence from the Swiss experience. Transport Policy, 55, 18-28.

Buehler, P. (2014). 9 Reasons the U.S. ended up so much more car-dependent than Europe. Retrieved from https://www.citylab.com

Bernama. (2017). Penang's traffic woes, a bane for locals and tourist. Retrieved from https://www.thesundaily.my

Buletin Mutiara. (2017). Penang to be first cycling state. Retrieved from https://www.buletinmutiara.com

Buck, D., \& Buehler, R. (2011). Bike lanes and other determinants of capital bikeshare trips. The Transportation Research Board Annual Meeting 2012 Conference, Washington DC. Retrieved from http://ralphbu.files.wordpress.com 
Cycling Embassy of Denmark Annual Report. (2018). Let us promote cycling in cities around the world together. Retrieved from http://www.cycling-embassy.dk

DeMaio, P. (2009). Bike-sharing: History, impacts, models of provision, and future. Journal of Public Transportation, 12(4), 41-56.

Erçetin, C. (2014). Planning and management of bike sharing systems for sustainable urban transport: Konya, Kayseri and Istanbul cases (PhD dissertation). Retrieved from Middle East Technical University.

Fishman, E., Washington, S., \& Haworth, N. (2012). Barriers and facilitators to public bicycle scheme use: A qualitative approach. Transportation Research Part F: Traffic Psychology and Behaviour, 15(6), 686-698.

Fishman, E., Washington, S., \& Haworth, N. (2013). Bike share: a synthesis of the literature. Transport Reviews, 33(2), 148-165.

Fishman, E. (2016). Bikeshare: A review of recent literature. Transport Reviews, 36(1), 92-113.

Fuller, D., Gauvin, L., Kestens, Y., Daniel, M., Fournier, M., Morency, P., \& Drouin, L. (2011). Use of a new public bicycle share program in Montreal, Canada. American Journal of Preventive Medicine, 41(1), 80-83.

Guo Y., Zhou J., Wu Y., \& Li Z. (2017). Identifying the factors affecting bike-sharing usage and degree of satisfaction in Ningbo, China. PloS ONE 12(9). https://doi.org/10.1371/journal.pone.0185100

Ladin, M.A., Das, A.M., Najah, A., Ismail, A., \& Rahmat, R.A.A.O. (2014). A review of strategies to implement sustainable urban transportation options in Malaysia. Jurnal Teknologi, 69(2). 85-90.

Lim, G.E. (2016). Making Penang a cleaner, green, safer, healthier and happier state. Retrieved from https://dapmalaysia.org

LinkBike Report. (2017). Fast Rent Bike (PG).

Martin, E., Cohen A., Botha, J., \& Shaheen, S. (2016). Bikesharing and bicycle safety (Report 12-54). USA, Minnesota Transportation Institute.

Mateo-Babiano, I. (2015). Public bicycle sharing in Asian cities. Journal of the Eastern Asia Society for Transportation Studies, 11, 60-74.

Mateo-Babiano, I., Kumar, S., \& Mejia, A. (2017). Bicycle sharing in Asia: a stakeholder perception and possible futures. Transportation Research Procedia, 25, 4966-4978.

Midgley, P. (2009). The role of smart bike-sharing systems in urban mobility. Journeys, 2(1), 2331.

Mohd Noor H., Azlima M., \& Rosmiza M.Z. (2018). Aktiviti berbasikal: Pemangkin kelestarian kampus, Geografia-Malaysian Journal of Society and Space, 14(3), 85-100.

Parkes, S.D., Marsden, G., Shaheen, S.A., \& Cohen, A.P. (2013). Understanding the diffusion of public bikesharing systems: Evidence from Europe and North America. Journal of Transport Geography, 31, 94-103.

Ong, J.Y. (2017). Penang a step closer to becoming a bicycle friendly state. Retrieved from http://www.thesundaily.my

Pavither. (2018). Penang opens country's first spiral bridge for bicycle, pedestrians. Retrieved from https://www.propertyguru.com.my

Pucher, J.R., \& Buehler, R. (Eds.). (2012). City cycling. Cambridge, MA, The MIT Press. 
Sekaran, R. (2018). Group celebrates three years of commuting together on bicycles to work every Friday. Retrieved from https://www.thestar.com.my

Shaheen, S.A., Guzman, S., \& Zhang, H. (2010). Bikesharing in Europe, the Americas, and Asia. Transportation Research Record: Journal of the Transportation Research Board, 2143, 159167.

Shaheen, S, Zhang, H, Martin, E., \& Guzman, S. (2011). Hangzhou public bicycle: Understanding early adoption and behavioral response to bikesharing in Hangzhou, China. Transportation Research Record, 2247, 34-41.

Shaheen, S., Guzman, S., \& Zhang, H. (2012). Bikesharing across the globe. In Pucher, J. \& Buehler, R. (Eds.), City cycling (pp.183-210). Cambridge, MA, The MIT Press.

Shaheen, S., Cohen, A., \& Martin, E. (2013). Public bikesharing in North America: Early operator understanding and emerging trends. Transportation Research Record: Journal of the Transportation Research Board, 2387, 83-92.

Taha, N.W. (2018). Sistem Perkongsian Basikal: Kajian Kes di George Town (Masters dissertation). Retrieved from School of Humanities, Universiti Sains Malaysia.

The Bikeshare Planning Guide. (2018). The Institute for Transportation and Development Policy. Walker, P. (2017). How cycling can save the world. New York, Penguin.

Wiersma, B. (2010). Bicycle sharing system: Role, effects and application to Plymouth (Masters dissertation). Retrieved from University of Groningen. 